\title{
ПРОЦЕССЫ РЕФОРМИРОВАНИЯ ОТЕЧЕСТВЕННОЙ СИСТЕМЫ ОБРАЩЕНИЯ С ОТХОДАМИ ПРОИЗВОДСТВА И ПОТРЕБЛЕНИЯ
}

\author{
(c) 2019 Пухова Марина Михайловна \\ кандидат экономических наук, \\ доцент Департамента корпоративных финансов и корпоративного управления \\ Финансовый университет при Правительстве Российской Федерации, Россия, Москва \\ E-mail:mpuhova@fa.ru
}

Статья подготовлена по результатам научно-исследовательской работы, выполняемой в рамках государственного задания в ФГОБУ ВО «Финансовый университет при Правительстве Российской Федерации» на 2019 год. В статье отражены элементы реформирования системы обращения с отходами производства и потребления. Обозначена специфика формирования региональных операторов по обращению с твердыми коммунальными отходами, территориальных схем обращения с отходами, а также принципа 3R.

Ключевые слова: отрасль обращения с отходами производства и потребления, региональные операторы, территориальная схема

В настоящее время происходит реформирование отрасли обращения с отходами производства и потребления и осуществляется ее кардинальная перестройка. Современная политика в области реформирования данной системы обращения с отходами делает основной акцент на вторичной переработке отходов, в т.ч. использовании принципов 3R. Также стоит отметить, что до 2019 года данная сфера носила по всей стране преимущественно локальный характер, в т.ч. в каждом регионе были отдельные частные и муниципальные компании, которые занимались вывозом и утилизацией мусора. Как отмечается, до $70 \%$ расчетов производились наличными и мусор вывозился на полигоны или несанкционированные свалки [1]. В Российской Федерации ежегодно образуется более 60 млн. тонн твердых бытовых отходов или около 400 кг в расчете на 1 человека в год [2]. Таким образом, формирование эффективно функционирующей комплексной системы обращения с отходами является одной из наиболее актуальных задач, обозначенной в Стратегии развития промышленности по обработке, утилизации и обезвреживанию отходов производства и потребления на период до 2030 года, утвержденной Распоряжением Правительства Российской Федерации от 25 января 2018 г. № 84-p.

В данном аспекте в части реформирования указанной отрасли серьезным изменением стало внесение поправки в ст. 24.6 Федерального закона от 24.06.1998 № 89-Ф3 «Об отходах производ- ства и потребления», а именно формирование региональных операторов по обращению с твердыми коммунальными отходами (далее - ТКО), которые создают новые условия деятельности на рынке обращения с отходами. Необходимо отметить, что данными операторами являются юридические лица, которые заключают договор на оказание услуг по обращению с ТКО с непосредственными их собственниками. Таким образом, в каждом субъекте РФ образованы один или несколько региональных операторов, отобранные на конкурсной основе и которые оказывают услуги по сбору, транспортировке, обработке, утилизации, обезвреживанию, захоронению ТКО в соответствии с правилами обращения. При этом региональный оператор полностью несет ответственность перед субъектом РФ за работу с отходами в пределах территориальной схемы обращения с отходами. В свою очередь, указанную схему разрабатывает и утверждает субъект РФ в соответствии с документацией по территориальному планированию. Порядок разработки, утверждении, корректировки территориальных схем обращения с отходами определен Постановлением Правительства РФ от 22.09.2018 № 1130 «О разработке, общественном обсуждении, утверждении, корректировке территориальных схем в области обращения с отходами производства и потребления, в том числе с твердыми коммунальными отходами, а также о требованиях к составу и содержанию таких схем». 
Важно подчеркнуть, что к территориальной схеме обращения с отходами предъявляются серьезные требования согласно 89-ФЗ, в т.ч. указанная схема должна содержать следующие данные: об источниках отходов с их указанием на карте субъекта, данные о количестве отходов с классификацией по степени опасности, целевые показатели по утилизации, обезвреживанию и размещению отходов, о месте нахождения объектов по обращению с отходами, которые должны быть включены в государственный реестр объектов размещения отходов, о планируемом строительстве указанных объектов, электронную модель всей территориальной схемы и пр.

Важно отметить, что в связи с вступлением в силу Федерального закона от 31 декабря 2017 года № 505-ФЗ «О внесении изменений в Федеральный закон «Об отходах производства и потребления» и отдельные законодательные акты Российской Федерации» с 1 января 2019 года, соглашение между органами исполнительной власти субъектов Российской Федерации и региональными операторами заключалось не позднее 1 мая 2018 года.

Необходимо подчеркнуть, что услуга по обращению с ТКО стала коммунальной и выделена отдельной строкой: обращение с ТКО. Тарификация в данной отрасли регулируется Постановлением Правительства РФ от 30.05.2016 № 484 «О ценообразовании в области обращения с твердыми коммунальными отходами» (вместе с «Правилами регулирования тарифов в сфере обращения с твердыми коммунальными отходами»). Однако не во всех регионах размер тарифа является прозрачным и понятным для населения.

Также представляется важным обозначить проблему, которая не позволяет сформировать необходимую инфраструктуру по переработке отходов и выражается в отсутствии системы и культуры населения по раздельному сбору мусора. Данная практика получила широкое распространение в зарубежных странах и успешно реализуется в них. Например, тарифы услуги по сбору раздельного мусора существенно ниже, чем неотсортированного. Так, с 2015 года в Германии введена единая система селективного сбора мусора, которая предполагает разделение ТКО на биомассу, макулатуру, стекло, металлы и пластмассы. Для каждого вида мусора уста- новлены отдельные разноцветные контейнеры: голубой предназначен для бумажных изделий; желтый - для предметов со знаком «зеленая точка»*; зеленый - для органических отходов. Старые батарейки сдаются в приемные пункты в магазинах. В Германия перерабатывается таким образом 66\% мусора [3].

Необходимо подчеркнуть, что система раздельного сбор мусора является неотъемлемым элементом территориальной системы обращения с отходами, но должная инфраструктура для ее эффективной реализации не создана. Если в регионе ведется раздельный сбор мусора, но инфраструктура не создана, то от общего объема отходов на переработку уйдет только $2 \%$. Если есть мусоросортировочное предприятие, но не ведется раздельного сбора мусора, то до 10 [4].

Важно отметить создание Российского экологического оператора, функции которого возложены на Министерство природных ресурсов и экологии Российской Федерации, в соответствии с Указом Президента РФ от 14.01.2019 № 8 «О создании публично-правовой компании по формированию комплексной системы обращения с твердыми коммунальными отходами «Российский экологический оператор». Данный оператор сформирован в целях реализации Национального проекта «Экология» и включает в себя следующие основные функции: координация деятельности органов исполнительной власти разных уровней, меры стимулирования и поддержки для вторичной переработки отходов и др.

Если проанализировать структуру управления компанией «Российский экологический оператор», то органами управления являются наблюдательный совет, правление и генеральный директор. При этом высшим органом управления является наблюдательный совет, который назначается Правительством Российской Федерации. В данном аспекте целесообразно отметить, что система управления в указанной компании сформирована по аналогии с системой управления в государственных корпорациях (Росатом, Роскосмос, Ростех и др.), каждая из которой была образована на основе принятия отдельного Федерального закона. В настоящее время пока нельзя проанализировать эффективность деятельности Российского экологического оператора, хотя в его полномочия входят:

\footnotetext{
* Производители и торговые компании заключили договор с Duales System и платят взносы для организации сбора упаковок, подлежащих утилизации
} 
осуществление инвестиционной деятельности, иной деятельности, приносящей доход для достижения цели. Таким образом, целесообразно принять перечень нормативно-правовых документов, которые позволят соблюдать максимальную транспарентность деятельности публично-правовой компании.

Если говорить о формировании принципов $3 \mathrm{R}$ технологий по переработке отходов, то эта система включает в себя три составляющих: Reduce, Reuse, Recycle (снижение, вторичное использование, переработка отходов), в т.ч. формирование «культуры нулевых отходов». В данном аспекте концепция $5 \mathrm{R}$ или Zero Waste («ноль отходов», «ноль потерь») становится в настоящее время все более популярной и основана на сокращении количества производимого нами мусора. Основная цель данной концепции заключается в том, чтобы мусор не попадал на свалку или на предприятие.

Принципы 5R выглядят следующим образом [5]:

1. Refuse (отказ) - отказ в своей жизнедеятельности от ненужных вещей.

2. Reduce (уменьшение потребления) уменьшение потребления ненужных вещей, которые потом подлежат выбросу.

3. Reuse+Repair (повторное использование и ремонт) - бережное отношение к предметам потребления, их повторное использование или ремонт.

4. Recycle (переработка) - переработка того мусора, который накопился.

5. Rot (компостирование) - создание компоста из живой органики.

Необходимо отметить, что государственная политика в отношении формирования отрасли по обращению с отходами относится к макроуровню и создает национальную единую систе- му с помощью принятия нормативно-правовых актов, регулирующих взаимосвязь каждого ее элемента на разных уровнях управления. На микроуровне для реализации национальной политики отдельные компании применяют разные стандарты, подтверждающие качество товаров и услуг, системы управления, экологического менеджмента и т.п. Например, международный стандарт ISO 14001:2015 является важным регулирующим документов в области экологического менеджмента с акцентом на стратегическое планирование. Стандарт предполагает системный подход к решению проблем в области защиты окружающей среды от негативного влияния на нее, вовлекая все уровни компании в систему экологического менеджмента. Он определяет прежде всего установленные требования к системе экологического менеджмента организаций, которые нацелены на сохранение окружающей среды, улучшение экологических показателей и достижение экологических целей.

В заключении необходимо отметить, что реформирование отрасли по обращению с отходами производства и потребления является длительным и сложным комплексным процессом. При этом очень важно, если каждый человек будет придерживаться реализации концепции «ноль отходов» и раздельного сбора мусора, то проблема образования большого количества несанкционированных полигонов постепенно решится. Для успешной реализации задач, обозначенных в Стратегии развития промышленности по обработке, утилизации и обезвреживанию отходов производства и потребления на период до 2030 года требуется воспитание социальной ответственности каждого индивидуума перед всем обществом, т.е. в данном аспекте важно осознание ответственности как перед обществом, так и перед будущим поколением.

\section{Библиографический список}

1. Мусорный передел. Как реформируют рынок утилизации и переработки отходов [Электронный ресурс].Режим доступа: https://www.rbc.ru/trends/law (дата обращения: 10.06.2019)

2. Лихачева О.И., Советов П.М. Методологические аспекты управления сферой обращения с твердыми бытовыми отходами// Экономические и социальные перемены: факты, тенденции, прогноз.- Том 10.- № 4.2017.- С.111-127

3. Раздельный сбор мусора: быть или не быть в России [Электронный ресурс].- Режим доступа: https:/tass. ru/spec/musor_sbor (дата обращения: 27.07.2019)

4. Петрова Е. Мусорная реформа: за что платят россияне [Электронный ресурс].- Режим доступа: https:// www.gazeta.ru/business/2019/02/01/12157543.shtml?updated (дата обращения: 11.06.2019)

5. Концепция «Ноль отходов» или «Zero Waste» [Электронный ресурс].- Режим доступа: https://minminds. com/zero-waste/\#_5R_Zero_Waste (дата обращения: 11.06.2019) 